\title{
Condicionamento osmótico e desempenho fisiológico de sementes de rúcula
}

\author{
Jarbas Alves \\ Rafael Marani Barbosa* \\ Denis Santiago da Costa \\ Marco Eustáquio de Sá \\ Universidade Estadual Paulista, Faculdade de Engenharia (FE/Unesp) \\ Avenida Brasil, 56, Centro, CEP 15385-000, Ilha Solteira - SP, Brasil \\ *Autor para correspondência \\ rmarani@gmail.com
}

Submetido em 29/06/2011

Aceito para publicação em 29/09/2011

\section{Resumo}

A rúcula é uma hortaliça folhosa que tem ganhado espaço na oferta de alimentos em várias regiões do Brasil. Sua multiplicação se dá unicamente por sementes e, sendo assim, torna-se imperioso o uso de material propagativo de alta qualidade para a implantação da lavoura. Estudos mostram que o condicionamento fisiológico de sementes promove melhorias na velocidade e na uniformidade do estabelecimento de plântulas no campo. Assim, o presente trabalho foi realizado com o objetivo de verificar o efeito do condicionamento osmótico sobre o desempenho de sementes de rúcula. Cinco lotes da cultivar Cultivada, foram submetidas ao condicionamento osmótico por 24 horas, utilizando-se os potenciais osmóticos de $0,0,-0,1,-0,2,-0,3 \mathrm{MPa}$, obtidas através de solução de Polietilenoglicol (Carbonax 6000). Utilizou-se o delineamento inteiramente casualizado com 20 tratamentos (5 lotes $\times 4$ potenciais osmóticos) e quatro repetições. As médias foram comparadas pelo teste de Tukey e análises de regressão para os potencias osmóticos. Os dados mostraram que o condicionamento osmótico provocou melhoria na germinação e na percentagem de plantas fortes em termos de vigor.

Palavras-chave: Classificação do vigor de plântulas, Eruca sativa, Polietilenoglicol (PEG), Vigor

\section{Abstract}

Priming and physiological performance of rocket salad seeds. Rocket salad is a leafy vegetable that has become a popular food in various regions of Brazil. Its multiplication is only possible with seeds and, therefore, high quality propagation material is necessary for establishing a good crop. Studies show that seed conditioning promotes physiological improvements in the speed and uniformity of seedling establishment in the field. The present work was carried out in order to verify the effect of priming on the performance of rocket salad seeds. Five seed lots of rocket salad, cultivar Cultivada, were primed for 24 hours, using the potentials of $0.0,-0.1$, $-0.2,-0.3 \mathrm{MPa}$, in a polyethylene glycol (Carbonax 6000) solution. A completely randomized design with 20 treatments $(5$ seed lots $\times 4$ potentials) was used, with four replications. Means were compared by Tukey's test and regression analyses were conducted for the osmotic potential. The data showed that priming improved germination and the percentage of strong plants in relation to vigor.

Key words: Eruca sativa, Polyethylene glycol, Seedling vigor classification, Vigor 
O uso de sementes de alta qualidade é um fator fundamental na implantação de uma cultura, pois, somente assim, pode-se ter resposta aos outros objetivos como nutrição adequada da planta, sanidade da lavoura e benefícios em produtividade em função do melhoramento genético.

Um dos fatores limitantes para o sucesso das culturas tem sido a dificuldade de se obter sementes capazes de proporcionar o estabelecimento da cultura com população ideal e com plântulas uniformes e vigorosas. Os agricultores têm exigido, cada vez mais, sementes de alta qualidade, que possibilitem a emergência rápida e uniforme no campo (KIKUTI et al., 2002). Tendo em vista os fatores que provocam problemas no processo de germinação, emergência de plântulas e estabelecimento do estande, resultando em prejuízos econômicos ao produtor, a utilização de técnicas como beneficiamento adequado, o tratamento de sementes e o condicionamento fisiológico têm sido desenvolvidos com o objetivo de beneficiar o desempenho das sementes em campo.

Diversos são os procedimentos propostos para realizar o condicionamento fisiológico, no entanto, o procedimento adotado pode influenciar os resultados. De maneira geral, têm sido utilizadas as técnicas de hidrocondicionamento (com utilização exclusiva de água para a hidratação das sementes) e de osmocondicionamento (emprego de soluções de polietilenoglicol, manitol e sais) embora existam, também, outras técnicas como matricondicionamento (que envolve o uso de materiais como argila, vermiculita, areia e turfa) e exposição das sementes à atmosfera úmida a pré-germinação (MARCOS FILHO, 2005). Dentre esses tratamentos, destaca-se o condicionamento osmótico, que é uma técnica que envolve o controle da hidratação das sementes por meio da utilização de indutores de restrição hídrica, sendo suficiente para permitir os processos preparatórios essenciais à germinação, porém não permite ocorrência da protrusão da raiz primária (BRADFORD, 1986).

O condicionamento osmótico de sementes está intimamente ligado aos conhecimentos e metodologias até então elaboradas por diversos trabalhos de pesquisa, entretanto, para rúcula (Eruca sativa L.) pouco se conhece sobre o efeito dessa técnica. Assim, o desenvolvimento e aprimoramento de técnicas que acelerem o período para que ocorra a germinação e emergência das plântulas em campo são de extrema importância para a agricultura.

O presente trabalho foi realizado com o objetivo de se verificar o efeito do condicionamento osmótico sobre o desempenho de cinco lotes de sementes de rúcula.

O experimento foi realizado no Laboratório de Análise de Sementes da Faculdade de Engenharia, UNESP - Campus de Ilha Solteira, durante o ano de 2009. Para a realização do experimento foram utilizados cinco lotes comerciais de sementes de rúcula, cultivar Cultivada. Foi submetido ao condicionamento osmótico, aproximadamente, $1 \mathrm{~g}$ de sementes para cada lote, e o condicionamento constou da imersão das sementes em soluções de Polietilenoglicol (Carbonax 6000) preparadas para se obter os potenciais osmóticos de 0,0 (controle: água destilada); $-0,1 ;-0,2 ;-0,3 \mathrm{MPa}(0,0 \mathrm{~atm}$, $-1,0 \mathrm{~atm},-2,0 \mathrm{~atm},-3,0 \mathrm{~atm})$.

Para calcular a quantidade de produto utilizou-se a fórmula de Van't Hoff: $\psi_{o s}=-R \cdot T \cdot C$. Onde: $\psi_{\text {os }}=$ Potencial Osmótico (atm), R= 0,082 (atm.L. $\left.\mathrm{mol}^{-1} \cdot \mathrm{K}^{-1}\right)$,

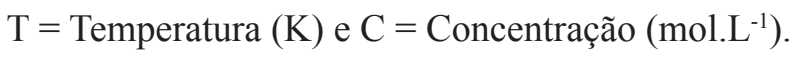

As soluções foram preparadas e as sementes imersas por $24 \mathrm{~h}$ sob temperatura constante de $20^{\circ} \mathrm{C}$ e então retiradas e secas a $38{ }^{\circ} \mathrm{C}$ por mais $24 \mathrm{~h}$ e posteriormente submetidas às seguintes avaliações:

Teste de germinação: quatro repetições de 50 sementes tratamento foram semeadas em caixas de plástico transparentes $(11,5 \times 11,5 \times 3,5 \mathrm{~cm})$ contendo no interior uma camada de papel previamente umedecido com quantidades de água equivalente a 2,5 vezes a massa do papel seco. Após a instalação as caixas foram mantidas em câmara de germinação a $25^{\circ} \mathrm{C}$. As contagens foram realizadas aos quatro e sete dias após a instalação do teste (BRASIL, 2009).

Índice de velocidade de Germinação IVG: realizado em conjunto com o teste de germinação com leituras realizadas diariamente. $\mathrm{O}$ índice foi calculado pela fórmula proposta por Maguire (1962).

Classificação do vigor de plântulas: As plântulas normais da primeira contagem de germinação foram 
removidas e computadas como normais fortes (vigorosas). As plântulas remanescentes permaneceram no teste até contagem final e as que apresentaram desenvolvimento normal foram classificadas em fortes, médias e fracas, por meio de avaliação visual. As plântulas foram contadas e os resultados expressos em porcentagem (NAKAGAWA, 1999).

Foi utilizado o delineamento inteiramente casualizado, com 20 tratamentos em esquema fatorial $5 \times 4$ (lotes $\times$ potenciais osmóticos), com quatro repetições. Os dados foram submetidos à análise de variância (ANOVA) e as médias comparadas pelo teste Tukey a $5 \%$ de probabilidade. A análise de regressão foi realizada para os potenciais osmóticos (BANZATTO; KRONKA, 2006).

$\mathrm{Na}$ Tabela 1 estão contidos os valores de F obtidos pela análise de variância e graus de liberdade dos fatores. Foram observadas diferenças significativas entre os lotes indicação de alguma função significativa para os potenciais osmóticos, porém não foram observadas interações entre os fatores lotes e potencial osmótico.

Foi possível verificar que os lotes 2 e 5 foram os que tiveram o maior potencial de germinação, e os lotes 1, 3 e 4 potencial reduzido, mas ainda assim todos os lotes apresentam germinação acima de $75 \%$ que é o limite mínimo para comercialização (BRASIL, 1986). (Tabela 2). Em relação ao vigor de sementes, estimado pelo IVG, foi possível separar os lotes em diferentes níveis de vigor, onde prevaleceram os lotes 2 e 5 como de alto vigor e os lotes 1, 3 e 4 como de baixo vigor. Com a classificação de vigor, no que se refere às plântulas fortes ou mais vigorosas, os lotes foram estratificados em cinco distintos níveis de vigor, sendo que o lote que apresentou maior número de plântulas vigorosas (lote 5) apresentou, concomitantemente, menor número de plântulas fracas, como identificado pelo procedimento estatístico. Ainda, no tocante à classificação do vigor das plântulas, os lotes 1 e 3 apresentaram valores de vigor intermediário entre os lotes. Assim, de acordo com o teste de classificação de plântulas, podem-se estratificar os lotes em três níveis distintos de vigor: os lotes 2 e 5 foram classificados como de alto vigor, lotes 1 e 3 apresentaram vigor intermediário e o lote 4 , baixo vigor.

TABELA 2: Germinação (Germ), índice de velocidade de germinação (IVG) e classificação do vigor de plântulas: fortes (Pfo), médias (Pm) e fracas (Pfr) de cinco lotes de sementes de rúcula, submetidos a diferentes níveis de potencial osmótico. Ilha Solteira, 2009.

\begin{tabular}{ccccccc}
\hline \multirow{2}{*}{ Tratamentos } & $\begin{array}{c}\text { Germ. } \\
\%\end{array}$ & IVG & Pfo & Pm & Pfr \\
\hline Lotes & & & & & $\%$ \\
1 & $92 \mathrm{~b}^{*}$ & $11,3 \mathrm{c}$ & $57,3 \mathrm{c}$ & $29,3 \mathrm{bc}$ & $5,8 \mathrm{~d}$ \\
2 & $96 \mathrm{a}$ & $11,9 \mathrm{ab}$ & $60,8 \mathrm{~b}$ & $27,3 \mathrm{bc}$ & $8,4 \mathrm{c}$ \\
3 & $91 \mathrm{~b}$ & $11,1 \mathrm{c}$ & $45,6 \mathrm{~d}$ & $30,6 \mathrm{ab}$ & $14,4 \mathrm{~b}$ \\
4 & $93 \mathrm{~b}$ & $11,6 \mathrm{bc}$ & $41,1 \mathrm{e}$ & $33,4 \mathrm{a}$ & $18,4 \mathrm{a}$ \\
5 & $96 \mathrm{a}$ & $12,1 \mathrm{a}$ & $64,1 \mathrm{a}$ & $25,8 \mathrm{c}$ & $6,4 \mathrm{~cd}$
\end{tabular}

\section{Potenciais osmóticos}

\begin{tabular}{cccccc}
0 atm & 91 & 11,3 & 48,3 & 30,1 & 12,3 \\
$-1 \mathrm{~atm}$ & 92 & 11,7 & 53,6 & 29,6 & 10,6 \\
$-2 \mathrm{~atm}$ & 95 & 11,7 & 55,7 & 29,6 & 10,2 \\
$-3 \mathrm{~atm}$ & 95 & 11,7 & 57,5 & 27,7 & 9,5 \\
\hline Média Geral & 93,68 & 11,61 & 53,78 & 29,25 & 10,65 \\
CV (\%) & 2,95 & 3,21 & 5,8 & 13,12 & 23,43 \\
\hline
\end{tabular}

${ }^{*}$ Médias seguidas por letras distintas diferem entre si, ao nível de significância de 5\%, pelo teste de Tukey.

TABELA 1: Análise de variância de níveis de potencial osmótico em diferentes lotes de sementes de rúcula. Ilha Solteira, 2009.

\begin{tabular}{|c|c|c|c|c|c|c|}
\hline \multirow{3}{*}{$\begin{array}{l}\text { Causas de } \\
\text { Variação }\end{array}$} & \multirow{3}{*}{$\begin{array}{c}\text { Graus de } \\
\text { Liberdade }\end{array}$} & \multicolumn{5}{|c|}{ Valores de F } \\
\hline & & \multirow{2}{*}{ Germ. } & \multirow{2}{*}{ IVG } & \multicolumn{3}{|c|}{ Classificação do vigor } \\
\hline & & & & Forte & Média & Fracas \\
\hline Lotes (A) & 4 & $13,55^{* *}$ & $18,21^{* *}$ & $162,14^{* *}$ & $9,55^{* *}$ & $77,72^{* *}$ \\
\hline Pot. osmótico (B) & 3 & $11,56^{* *}$ & $6,72^{* *}$ & $32,61^{* *}$ & 1,53 & $4,55^{* *}$ \\
\hline $\mathrm{A} \times \mathrm{B}$ & 12 & $0,97^{\text {n.s. }}$ & $0,79^{\text {n.s. }}$ & $1,46^{\text {n.s. }}$ & $0,61^{\text {n.s. }}$ & $1,99^{*}$ \\
\hline
\end{tabular}

**, *, n.s. - Teste F significativo ao nível de $1 \%, 5 \%$ de probabilidade, e não significativo, respectivamente. 
O uso de lotes de baixo vigor deve ser evitado pelos agricultores, pois podem provocar atrasos na formação de mudas e assim desuniformidade no estabelecimento de plântulas. $\mathrm{O}$ rápido estabelecimento da cultura no campo, proporcionado por lotes de alto vigor, implica em menores riscos, uma vez que a germinação das sementes e a emergência das plântulas podem ser marcadamente reduzidas pela ação de microrganismos (NASCIMENTO, 2005) e pelo menor desenvolvimento de plantas daninhas na área de cultivo (RONCHI et al., 2010).

Para os níveis de potenciais osmóticos verificou-se que as sementes embebidas na solução de PEG 6000 apresentaram valores superiores ao da testemunha (água pura), com maiores níveis de germinação. Os dados obtidos ajustaram-se a função quadrática, y $=-0,975 \mathrm{x}^{2}+3,505 \mathrm{x}+92,22$, com ponto máximo de 95,4\% (Figura 1).

Foi observado que o condicionamento osmótico de sementes pode ser utilizado em sementes de rúcula para melhorar o desempenho da germinação e estabelecimento de plântulas. A menor germinação, apresentada pelo potencial osmótico de 0 atm, já era esperada, pois por ocasião da imersão das sementes nas soluções foi possível notar que algumas já haviam emitido a raiz primária tornando-se intolerante a dessecação. À medida que as sementes foram submersas em soluções com menores potenciais, verificou-se aumento no percentual de germinação, provavelmente devido às sementes atingirem a fase II e ativar os processos bioquímicos preparatórios que não foram revertidos após a secagem sendo, portanto, o condicionamento fisiológico favorável.

Segundo Bewley e Black (1994), a tolerância das sementes à desidratação diminui gradativamente com o decorrer das fases I (embebição) e II (processos bioquímicos e fisiológicos preparatórios à germinação), sendo perdida no início da fase III (protrusão da raiz primária). Outro fator que pode ter contribuído para o menor valor no potencial osmótico 0 atm é que a hidratação rápida das sementes não possibilitou tempo hábil para reestruturação das membranas, provocando liberação de exsudados e assim caracterizando o dano por embebição rápida (MARCOS FILHO, 2005).

A velocidade de germinação aumentou em sementes condicionadas em função do potencial da solução de PEG, da mesma forma como foi observado na germinação, sendo que maiores IVG foram encontrados no intervalo de -2 e -3 atm (Figura 2). Desta maneira, verificou-se que, o condicionamento de sementes por meio da imersão das mesmas em soluções com diferentes potenciais osmóticos foi benéfico às sementes de rúcula, pois possibilitou aumento no IVG, proporcionando a germinação rápida e uniforme.

O condicionamento de sementes por meio da imersão em solução de PEG 6000 promoveu aumento no número de plântulas fortes e redução no de plântulas fracas (Figura 3). Em sementes que apresentam qualidade fisiológica inferior, o condicionamento permite que estas expressem o seu potencial, refletido pelo aumento de percentual de plântulas fortes e redução de plântulas fracas.

Efeitos positivos do condicionamento osmótico têm sido relatados para sementes de hortaliças, principalmente porque nesse grupo de plantas o produto final é colhido durante o período vegetativo e o rendimento por área geralmente está relacionado com o desenvolvimento individual da planta. Nesses casos, o vigor das sementes pode afetar o crescimento vegetativo e estar frequentemente relacionado com o rendimento da cultura (TEKRONY; EGLI, 1991).

Considerando os resultados obtidos, pode-se concluir que, o condicionamento osmótico proporciona melhoria na qualidade das sementes aumentando o percentual de germinação e a velocidade de germinação e reduzindo a percentagem de plântulas fracas e aumentando as fortes. 
FIGURA 1: Germinação de sementes de rúcula em função do condicionamento fisiológico. Ilha Solteira, 2009.

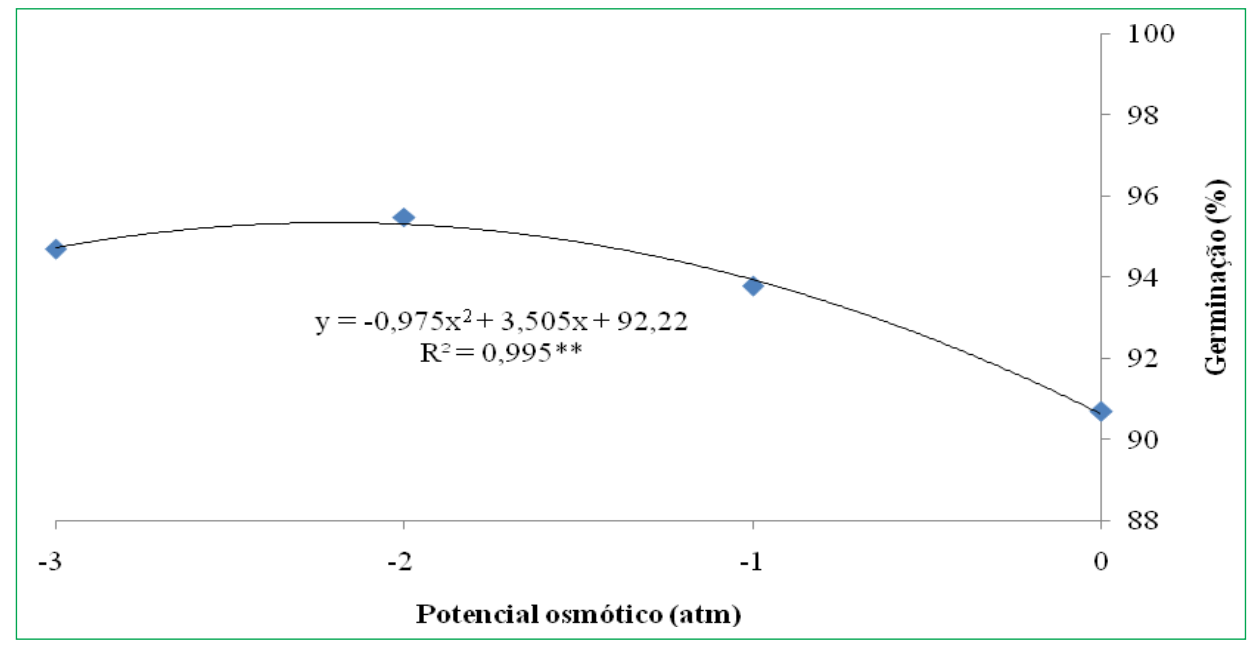

FIGURA 2: Índice de velocidade de germinação (IVG) de sementes de rúcula em função do condicionamento fisiológico. Ilha Solteira, 2009.

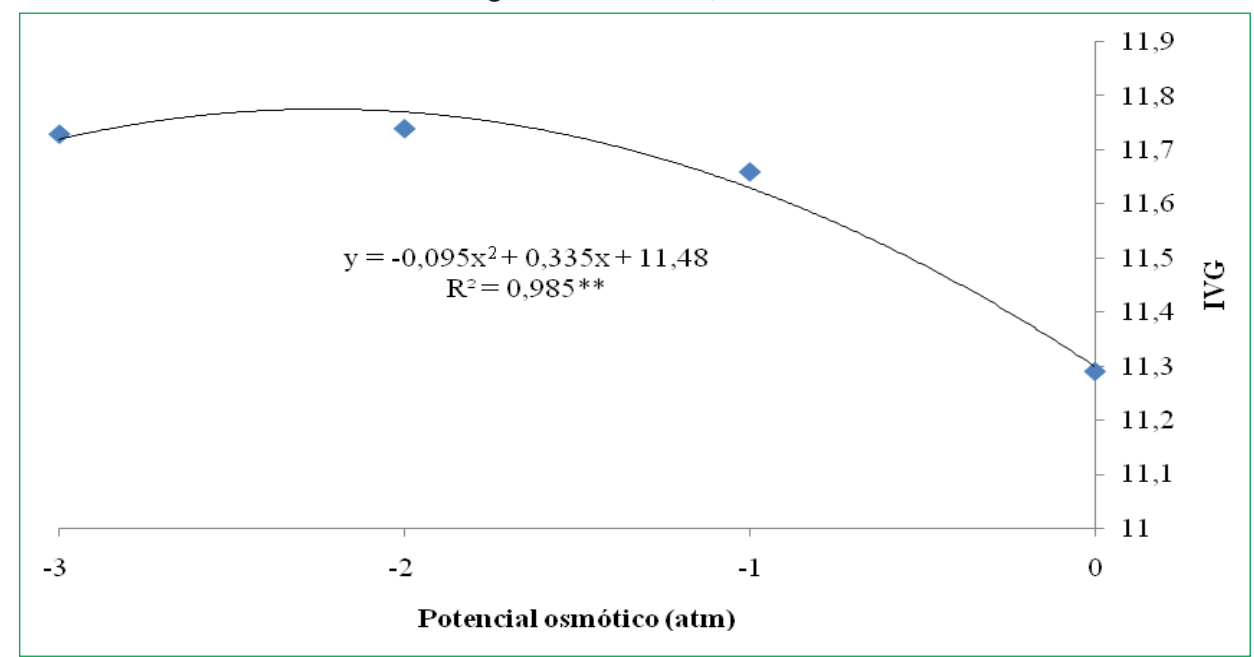

FIGURA 3: Classificação do vigor de plântulas de rúcula em função condicionamento fisiológico. Ilha Solteira, 2009.

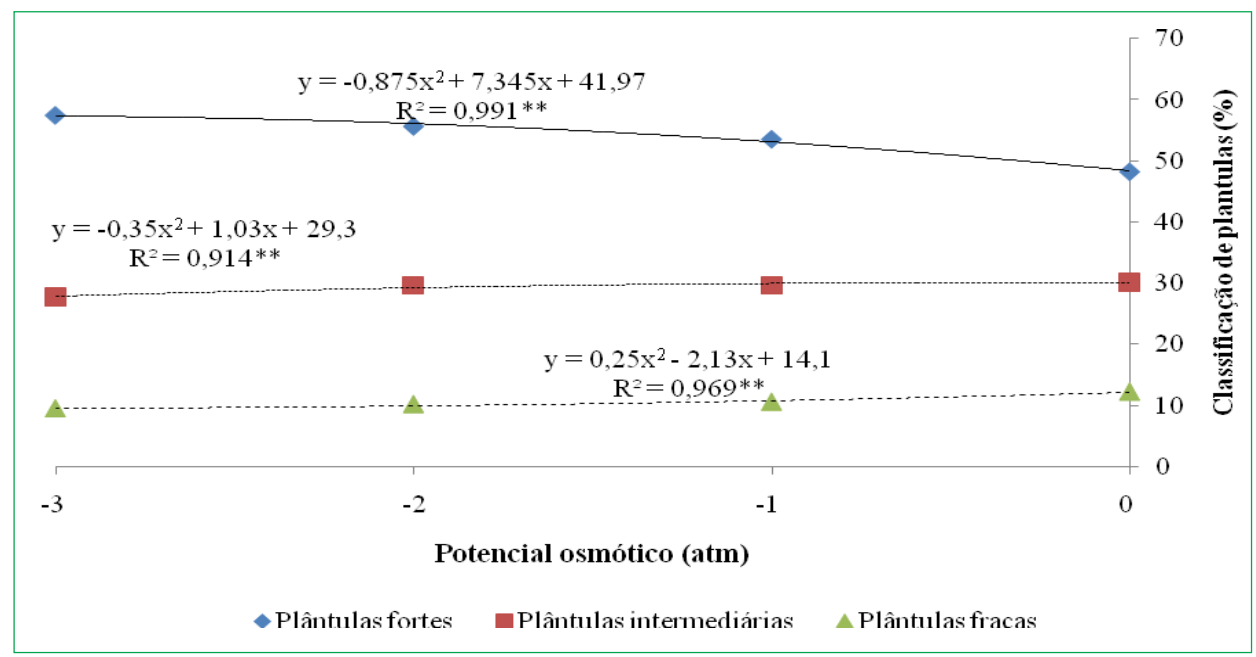




\section{Referências}

BANZATTO, D. A.; KRONKA, S. N. Experimentação agrícola. 4. ed. Jaboticabal: FUNEP, 2006. 237 p.

BEWLEY, J. D.; BLACK, M. Physiology of development and germination. New York: Plenum Press, 1994. 445 p.

BRADFORD, K. J. Manipulation of seed water relations via osmotic priming to improve germination under stress conditions. Horticulture Science, Alexandria, v. 21, n. 5, p. 1105-1112, 1986.

BRASIL. Portaria no 457, de 18 de dezembro de 1986. (Estabelece os padrões de sementes olerícolas para distribuição,...) Diário Oficial da República Federativa do Brasil, Poder Executivo, Brasilia, 23 dez. 1986, Seção 1, p.19653.

BRASIL. Ministério da Agricultura, Pecuária e Abastecimento. Regras para análise de sementes. Brasília, DF: Mapa/ACS, 2009. $395 \mathrm{p}$.

KIKUTI, A. L. P.; OLIVEIRA, J. A.; MEDEIROS FILHO, S.; FRAGA, A. C. Armazenamento e qualidade fisiológica de sementes de algodão submetidas ao condicionamento osmótico. Revista Ciência e Agrotecnologia, Lavras, v. 26, n. 2, p. 439-443, 2002.
MAGUIRE, J. D. Speed of germination and in selection and evaluation for seedling emergence and vigor. Crop Science, Madison, v. 2, n. 2, p. 176-177, 1962.

MARCOS FILHO, J. Fisiologia de sementes de plantas cultivadas. Piracicaba: Fealq, 2005. 495 p

NAKAGAWA, J. Testes de vigor baseados no desempenho das plântulas. In: KRZYZANOWSKI, F. C.; VIEIRA, R. D.; FRANÇA NETO, J. B. (Ed.). Vigor de sementes: conceitos e testes. Londrina: ABRATES, 1999. cap. 2, p. 2-21.

NASCIMENTO, W. M. Condicionamento osmótico de sementes de hortaliças visando a germinação em condições de temperaturas baixas. Horticultura Brasileira, Brasília, v. 23, n. 2, p. 211-214, 2005.

RONCHI, C. P.; SERRANO, L.A. L.; SILVA, A. A.; GUIMARAES, O. R. Manejo de plantas daninhas na cultura do tomateiro. Planta Daninha, Viçosa, v. 28, n. 1, p. 215-228, 2010.

TEKRONY, D. M.; EGLI, D. B. Relationship of seed vigor to crop yield: a review. Crop Science, Madison, v. 31, p. 816-822, 1991. 